\title{
Perfiles del alumnado de origen extranjero en centros con elevada presencia de escolares inmigrantes en el País Vasco
}

\author{
Foreign origin students' profiles in schools with a high presence \\ of immigrant scholars in the Basque Country
}

\section{EIDER AlKorta}

Universidad del PaísVasco/Euskal Herriko Unibertsitatea

\author{
Julia ShershneVa \\ Universidad del PaísVasco/Euskal Herriko Unibertsitatea \\ yulia.shershneva@ehu.eus (ESPAÑA)
}

Recibido: 03.072019

Aceptado: 13.04.2021

\section{RESUMEN}

En los últimos años han aumentado los estudios relacionados con el fenómeno de la concentración escolar a nivel europeo. El sistema educativo vasco tampoco es ajeno a estas dinámicas, aunque la literatura existente al respecto es bastante escasa. Este artículo tiene como objetivo describir los perfiles de las familias de origen extranjero que afirman que sus descendientes están matriculados en centros con elevada presencia de escolares inmigrantes. Para ello, hemos analizado las condiciones socioeconómicas de las familias inmigrantes, así como otros factores que pueden incidir en el fenómeno de la segregación escolar. En este sentido, el estudio vuelve a corroborar que las condiciones socioeconómicas inciden en el fenómeno de la segregación, pero, a su vez, apunta la necesidad de atender al conjunto de los factores que pueden influir en la misma. Así, se han detectado diferencias significativas en función del origen de las familias, poniendo de relieve la heterogeneidad del colectivo inmigrante, así como la necesidad de analizar la influencia que el sistema de modelos lingüísticos de la CAE tiene en la concentración escolar del alumnado inmigrante. 


\title{
PALABRAS CLAVE
}

Inmigración, segregación escolar, concentración escolar, exclusión social, sistema educativo.

\begin{abstract}
In recent years, studies related to the phenomenon of school concentration in Europe have increased. The education system of the Basque Country has also these dynamics, although the literature on this subject is quite scarce. The aim of the article is to describe the profiles of foreign students' families who consider that their children are studying in schools with a high presence of immigrants. To that end, we have analyzed the socioeconomic conditions of immigrant families, as well as other factors that may affect the phenomenon of school segregation. In this sense, our study corroborates that socioeconomic conditions affect the phenomenon of school segregation, but, in turn, points out the need to take into account other factors that may influence it. Thus, significant differences have been detected according to the origin of the families, highlighting the heterogeneity of the immigrant collective, as well as the need to analyze the influence that the system of linguistic models of the Basque Country has on immigrant students' school concentration.
\end{abstract}

\section{KEY WORDS}

Immigration, school segregation, school concentration, social exclusion, education system.

\section{INTRODUCCIÓN}

En los últimos años han aumentado los estudios relacionados con el fenómeno de la segregación y concentración escolar a nivel europeo. Tal y como señalan Murillo et al. (2017), la investigación sobre segregación escolar nace a finales de la década de los años 50 y principios de los 60. En estos años, los estudios se centraron en la pertenencia de los estudiantes a un grupo étnico predeterminado, aunque los estudios sobre esta temática han decrecido a la vez que aumenta el interés por la segregación escolar generada por el origen nacional del alumnado (Stroub y Richards, 2013; El-Habib et al., 2016; Entork y Lauk, 2008).

En el caso español, la investigación sobre segregación escolar es reciente y hay pocos trabajos que estimen su magnitud. Como señalan Murillo y Belavi (2018), esto puede ser por la poca disponibilidad de datos representativos para el conjunto del Estado, pero quizá también a un desinterés por conocer la profun- 
didad de la inequidad del sistema educativo. Apenas han pasado 10 años desde que se cuenta con grandes bases de datos que pueden aportar datos desagregados sobre la situación sociodemográfica de los estudiantes y sus familias. En este sentido, Schnepf (2007) apunta que la situación económica y la segregación escolar son factores determinantes en las desventajas que sufren las personas inmigrantes en los países de Europa Continental, por lo que resulta necesario analizar la segregación por origen y por nivel socioeconómico conjuntamente, diferenciando también la segregación existente en las escuelas públicas y privadas. Lee, Zhang y Stankov (2019) abogan por una medida compuesta que incorpore variables de ocupación, nivel educativo de los progenitores e ingresos familiares.

En la Comunidad Autónoma del País Vasco, en adelante CAE, el sistema educativo tampoco es ajeno a estas dinámicas, aunque la literatura académica existente al respecto es bastante escasa debido, en parte, a que el fenómeno de la inmigración extranjera es aún reciente en nuestro contexto. Aunque algunas de las características de la segregación escolar analizadas a nivel europeo y español se repiten en el caso vasco, la particularidad de los modelos lingüísticos, así como la dimensión de la dualidad de sus centros escolares en cuanto a la titularidad se refiere, evidencian la necesidad de investigar este fenómeno atendiendo a las diferencias existentes entre las comunidades autónomas.

Así, este artículo tiene como objetivo describir las características y perfiles de las familias que consideran que sus hijos e hijas están escolarizados en centros con elevada presencia de escolares inmigrantes. Para ello, tendremos en cuenta en qué medida influyen el origen, la situación económica familiar, los aspectos relacionados con el apoyo escolar recibido o el aislamiento percibido por cuestión de raza, religión o cultura o el hecho de que hayan sido orientados a un modelo lingüístico concreto, cuestión que adquiere una especial relevancia en el caso de la CAE, como veremos más adelante. Los resultados de nuestro estudio corroboran que las dinámicas de concentración están estrechamente relacionadas con las situaciones de pobreza y/o exclusión en sus diferentes dimensiones, pero, a su vez, ponen de relieve la importancia de analizar la influencia de otros factores como el origen y las características específicas del sistema educativo vasco. En el caso de la CAE, aunque los centros públicos escolarizan el mayor porcentaje de estudiantes inmigrantes de familias de menor $\operatorname{ISEC}^{1}(64,97 \%)$, los centros públicos tienen cifras más altas de segregación que los centros privados (Murillo y Belavi, 2018). Así, la segregación escolar de la población de origen extranjero es mayor dentro de la red pública a pesar de que la mayoría del alumnado de origen extranjero se encuentre matriculada en centros públicos. La segunda especificidad del sistema educativo vasco hace referencia a los modelos lingüísticos, y los resultados de la presente investigación evidencian la impor-

\footnotetext{
${ }^{1}$ El ISEC se refiere al nivel socioeconómico y cultural de las familias estudiantes que se construye a partir de las siguientes variables: Índice Socioeconómico Internacional de Situación Laboral, nivel educativo más alto de los padres del estudiante, índice PISA de la riqueza de la familia, índice PISA de recursos educativos del hogar y el índice PISA de posesiones con la cultura del domicilio familiar.
} 
tancia de analizar la influencia de este factor a la hora de analizar la segregación escolar de la población de origen extranjero. Además, se pone de relieve que dentro del colectivo inmigrante hay unas diferencias muy importantes en lo que se refiere a la situación económica, social y de capital cultural de las familias, y que estos perfiles se ven afectados de manera distinta por la concentración escolar. Por último, las diferencias por origen son fundamentales, debido a la heterogeneidad de situación y características socioeconómicas y culturales que presenta el colectivo inmigrante.

El artículo se estructura en cuatro apartados. En el primer apartado del artículo, realizamos un breve resumen de las aportaciones teóricas respecto al fenómeno de la segregación y concentración escolar. En un segundo apartado, realizaremos una descripción del sistema educativo vasco, así como un primer acercamiento a la realidad educativa del alumnado de origen extranjero en la CAE. En tercer lugar, señalaremos los aspectos metodológicos más relevantes del estudio para, a continuación, presentar los resultados del mismo. En último lugar, señalaremos las principales conclusiones de la investigación y realizaremos una serie de propuestas o líneas de investigación futuras para poder indagar mejor en el fenómeno de la concentración escolar del colectivo inmigrante.

\section{ANTECEDENTES TEÓRICOS}

En este apartado analizaremos las principales aportaciones teóricas en cuanto al fenómeno de la segregación y concentración escolar y explicaremos las características del sistema educativo vasco para poder contextualizar la(s) realidad(es) educativa(s) del alumnado inmigrante en la CAE.

Antes de ahondar en el fenómeno de la segregación y concentración escolar, cabe señalar que diferentes autores han puesto de relieve la existencia de discrepancias a la hora de definir estos conceptos. Capellán del Toro (2013) considera que en la medida que no se pueda observar que esa concentración se produce por mecanismos artificiales y que responde a un reparto "natural" de la población, no se debería hablar de segregación. Además, entiende que se debería reservar la expresión segregación para aquellas situaciones en las que se pueda mostrar el perjuicio que se causa a algunas de las partes implicadas en la situación de concentración. En la misma línea, Castaño y Olmos (2012) consideran que las segregaciones serían definidas como situaciones de separación entre distintos agentes colectivos vistas como no deseables.

La segregación escolar por origen es uno de los tipos de segregación existentes en el que se entiende la segregación como el fenómeno por el cual el alumnado se concentra en unas escuelas y no en otras (Murillo et al., 2017). Sin embargo, y tal y como corroboran diferentes estudios, nos referimos a un fenómeno multicausal por lo que resulta imprescindible analizar las características socioeconómicas y del sistema educativo para poder analizar el fenómeno en su globalidad. 
A este respecto, Castaño y Olmos (2012) señalan que al menos durante los primeros años de residencia, las personas inmigrantes se encuentran en condiciones de inferioridad respecto al resto de ciudadanos en aspectos como el trabajo, la vivienda, la cultura, y no sólo como individuos, también como grupo social. En el caso de la CAE, la inmigración extranjera es aún más reciente por lo que nuestra población objeto de estudio se encuentra en esa situación de desventaja que mencionan estos autores. Además, cabe señalar que las dinámicas de segregación están estrechamente ligadas a los mercados educativos locales, así como a las particularidades de las políticas educativas implementadas en cada país (Bonal y Bellei, 2018).

La importancia de analizar conjuntamente la magnitud de la segregación escolar por origen y por nivel socioeconómico y cultural de las familias es señalada por diferentes autores (Murillo y Belavi, 2018; Murillo y Graña, 2020). La escolarización del alumnado inmigrante descendiente de familias con mayor nivel socioeconómico y cultural es completamente diferente de aquella que tienen quienes han entrado en España de forma irregular o como consecuencia de procesos de reagrupación familiar. De esta forma, la segregación escolar de los estudiantes inmigrantes con menor nivel socioeconómico y cultural es superior a la de los inmigrantes, por un lado, y a la de estudiantes pertenecientes a familias de menor ISEC, por otro. No podemos olvidar que la población inmigrante es especialmente vulnerable a cualquier deficiencia en la calidad de la educación recibida, puesto que repercute de peor manera sobre la población cuya situación inicial es desventajosa (Murillo y Belavi, 2018).

Así mismo, y como ponen de relieve diferentes estudios a nivel internacional (Gorard y Smith, 2004; Orfield y Lee, 2005; Stephan, 2013, entre otros), resulta imprescindible analizar la influencia de la educación privada en la segregación escolar. Estos estudios señalan que el nivel de segregación escolar entre las escuelas públicas y privadas es cada vez mayor en términos de desigualdad socioeconómica de sus estudiantes. El estudio de Jenkins, Micklewrigh y Schnepf (2008) indica que la magnitud promedio de la segregación escolar por nivel socioeconómico en las escuelas privadas es de 0,11 puntos y de 0,008 en el caso de las públicas. En España, trabajos de Mancebón-Torrubia y Pérez-Ximénez de Embún (2009; 2010), Salinas y Santín (2012) y Bernal y Vera (2019) subrayan una relación positiva entre el nivel socioeconómico y la probabilidad de asistir a un centro concertado. Así, los hijos e hijas de inmigrantes y el alumnado que proviene de hogares con menos capital económico, social y cultural están más representados en centros públicos, y dentro de estos, en un espectro concreto; y el alumnado cuyos padres poseen mejores trabajos y mayores niveles de estudios y disponen de una mayor dotación de bienes y recursos culturales, están más representados en centros concertados o privados.

De todas formas, y tal y como hemos mencionado anteriormente, la segregación escolar del alumnado inmigrante en las escuelas públicas y privadas es poco abordada en la investigación española. Entre las investigaciones realizadas (Aja, 2000; Garreta, 2011; López-Falcón y Bayona, 2012; Colom i Ortiz, 2012; Peláez, 2012), podemos encontrar aquellas que consideran la segregación resi- 
dencial como factor de importancia en la segregación escolar. A este respecto, Murillo y Martínez-Garrido (2018) afirman que una gran parte de la segregación escolar es consecuencia de la segregación residencial, pero, a su vez, señalan que es un claro producto de las medidas políticas tomadas al respecto. Un ejemplo de ello residiría en el fomento de mecanismos de cuasi-mercado potenciando opciones de elección de centro que favorecen la segregación escolar. Bonal y Zancajo (2020) señalan que las pautas de movilidad educativa dependen en gran medida de las características de los mercados educativos locales. De esta manera, situaciones de infra o sobreoferta escolar, presencia de escuela concertada y niveles de segregación residencial se combinan para explicar pautas de movilidad y polarización social que perjudican especialmente al alumnado inmigrante y al alumnado en situación de pobreza. Al igual que otros autores (Allen, 2007; Bifulco, Ladd y Ross, 2009) concluyen que la segregación se reduce cuando aumenta la escolarización de proximidad.

En esta línea, autores como Burgess et al. (2005), Frankenberg (2013), Boterman (2013) o Kye (2018) hacen referencia al fenómeno conocido como native-flight o white-flight en el que las familias autóctonas retiran a sus hijos e hijas de los centros en los que predominan los estudiantes de origen extranjero, mientras que las inmigrantes, especialmente las menos favorecidas en términos socioeconómicos, escogen escuelas públicas para sus descendientes.

En el caso de la CAE también se confirma esta concentración de los estudiantes inmigrantes en los centros públicos, pero, a su vez, los datos nos muestran la importancia de analizar este fenómeno atendiendo a la casuística particular de cada Comunidad Autónoma. Así, la CAE es la única Comunidad Autónoma en la que los centros públicos tienen cifras más altas de segregación que los centros privados. Como señalan Murillo y Belavi (2018), esto alerta sobre el desempeño de los centros públicos de esta Comunidad respecto al grupo poblacional en cuestión, pues la segregación escolar dificulta la tarea de su escolarización e inclusión social. Además, en el caso vasco la concentración y segregación escolar tiene una particularidad en función de los modelos lingüísticos, aspecto que se tiene en cuenta en el presente estudio, puesto que hay diferencias significativas en la matriculación en los diferentes modelos lingüísticos entre la población autóctona y la de origen extranjero.

Así mismo, la importancia de la lengua vehicular de la escuela y su relación con el rendimiento escolar ha sido objeto de análisis en muchos estudios. Calero y Choi (2019) analizan los efectos de la inmersión lingüística en Cataluña y ponen de relieve las disfunciones que sufren los estudiantes cuya lengua materna no es el catalán. Los autores analizan los resultados de los estudiantes en diferentes competencias señalando las diferencias y las variables que influyen en ese rendimiento diferenciado. A su vez, señalan que hay unos perdedores en esa inmersión lingüística y mencionan las consecuencias que ello puede provocar en la trayectoria académica y laboral, y, por ende, en la inclusión social de una parte del alumnado catalán. En el caso de la CAE, nos encontramos con 
una sobrerrepresentación del alumnado inmigrante en el modelo $\mathrm{A}^{2}$, modelo de escolarización en castellano que representa uno de los factores que contribuyen a la segregación del alumnado en la CAE. A este respecto, Etxeberria et al. (2019) han evidenciado las diferencias de competencia oral en lengua vasca, siempre a favor del alumnado nativo. Además de la competencia linguística, Etxeberria et al. (2018) analizan las diferentes pautas del sistema de acogida y programas que se han puesto en marcha en la CAE. Hacen especial hincapié en la concentración del alumnado inmigrante que consideran uno de los primeros y principales obstáculos que una propuesta de educación inclusiva debe superar.

\section{EL ALUMNADO DE ORIGEN EXTRANJERO EN EL SISTEMA EDUCATIVO VASCO}

En este apartado, vamos a hacer una breve descripción del modelo educativo vasco, así como de la distribución del alumnado de origen extranjero dentro del mismo. Se trata de un primer acercamiento a la realidad educativa del alumnado de origen extranjero en la CAE, analizando su evolución, distribución por modelos lingüísticos y titularidad del centro en el que está matriculado. Por último, se analizan los datos relativos al Índice Socioeconómico y Cultural (ISEC), elaborado por el Instituto Vasco de Evaluación e Investigación Educativa (ISEI-IVEI) por estratos socioeconómicos.

Antes de describir las características que el alumnado de origen extranjero presenta en el sistema escolar vasco en comparación con el alumnado autóctono, vamos a señalar los principales ejes definitorios o rasgos principales del mismo. Así, la red educativa vasca está compuesta por dos tipos de centros en función de la titularidad de las mismas; la red de centros públicos y los centros privados que no están subvencionados por la Administración, mientras que la red privada incluye centros autorizados gestionados por entidades privadas. La mayoría de estos centros son concertados y están financiados con fondos públicos a través de conciertos educativos o subvenciones. Como se verá más adelante, prácticamente la mitad del alumnado está matriculada en centros de titularidad pública y la otra mitad en la red privada.

Otro de los rasgos que diferencia al sistema educativo vasco es el sistema de modelos lingüísticos, que, como se ha mencionado en el apartado teórico, añade una complejidad que tiene que ver con la concentración de los perfiles socioeconómicos en situación de mayor desventaja en ciertos estratos, especialmente en el modelo lingüístico A. En este sentido, es importante subrayar que se trata

2 El sistema educativo vasco se configura en base a tres modelos lingüísticos. El primer modelo denominado "modelo A" tiene al castellano como lengua vehicular, excepto en la asignatura de Lengua y Literatura Vasca. El modelo B, por su parte, se basa en la enseñanza de una parte de las asignaturas en castellano y otra en euskera y, por último, el modelo D tiene al euskera como lengua vehicular, excepto en la asignatura de Lengua y Literatura Castellana. El modelo X incluye al alumnado que actualmente no estudia euskara. 
de unas dinámicas previas a la llegada e incorporación del alumnado inmigrante, puesto que no es una problemática reciente.

Centrándonos en los datos de distribución del alumnado en el sistema de modelos lingüísticos, cabe mencionar que, aunque la mayoría del alumnado está matriculado en el modelo D, la matriculación por modelos lingüísticos varía según la titularidad de los centros, donde los centros públicos son los que aglutinan la mayor oferta de plazas en el modelo A. Así, en la red pública sube el porcentaje de alumnado matriculado en el modelo $\mathrm{D}(79,2 \%)$ y baja el porcentaje del alumnado matriculado en el modelo B (5,7\%). En los centros concertados o privados, en cambio, baja el porcentaje de alumnado matriculado en el modelo D hasta el 50,9\% y la mitad está matriculado en el modelo B $(31,3 \%)$ o en el modelo A (16,6\%) (Ver Gráfico 1).

Gráfico 1. Alumnado matriculado en enseñanzas de régimen general no universitarias en la CAE según titularidad del centro y modelo lingüístico $(2018 / 2019)$

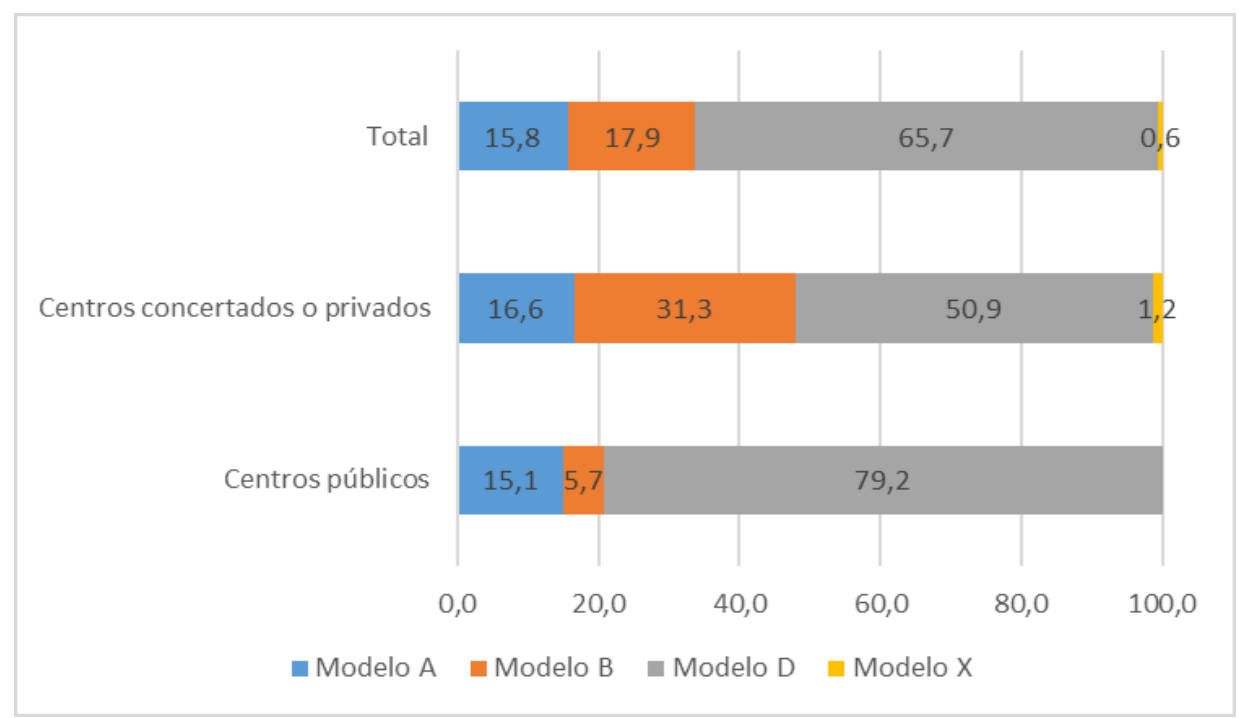

Fuente: Elaboración propia a partir de Eustat

Una vez que hemos expuesto los principales rasgos del sistema escolar vasco, vamos a presentar los datos del alumnado nacido en el extranjero. Atendiendo a su evolución, tal y como podemos ver en el Gráfico 2, el porcentaje de alumnado de origen extranjero en la CAE permanece constante en el periodo 2010-2019, aunque ha crecido en números absolutos desde el curso 2013/2014. Así, en el 2013/2014 había 24.031 alumnos y alumnas de origen extranjero, cifra que aumenta hasta 29.271 en el periodo 2018/2019. 


\section{Gráfico 2. Evolución del alumnado nacido en el extranjero y autóctono en la CAE} (2010-2019)

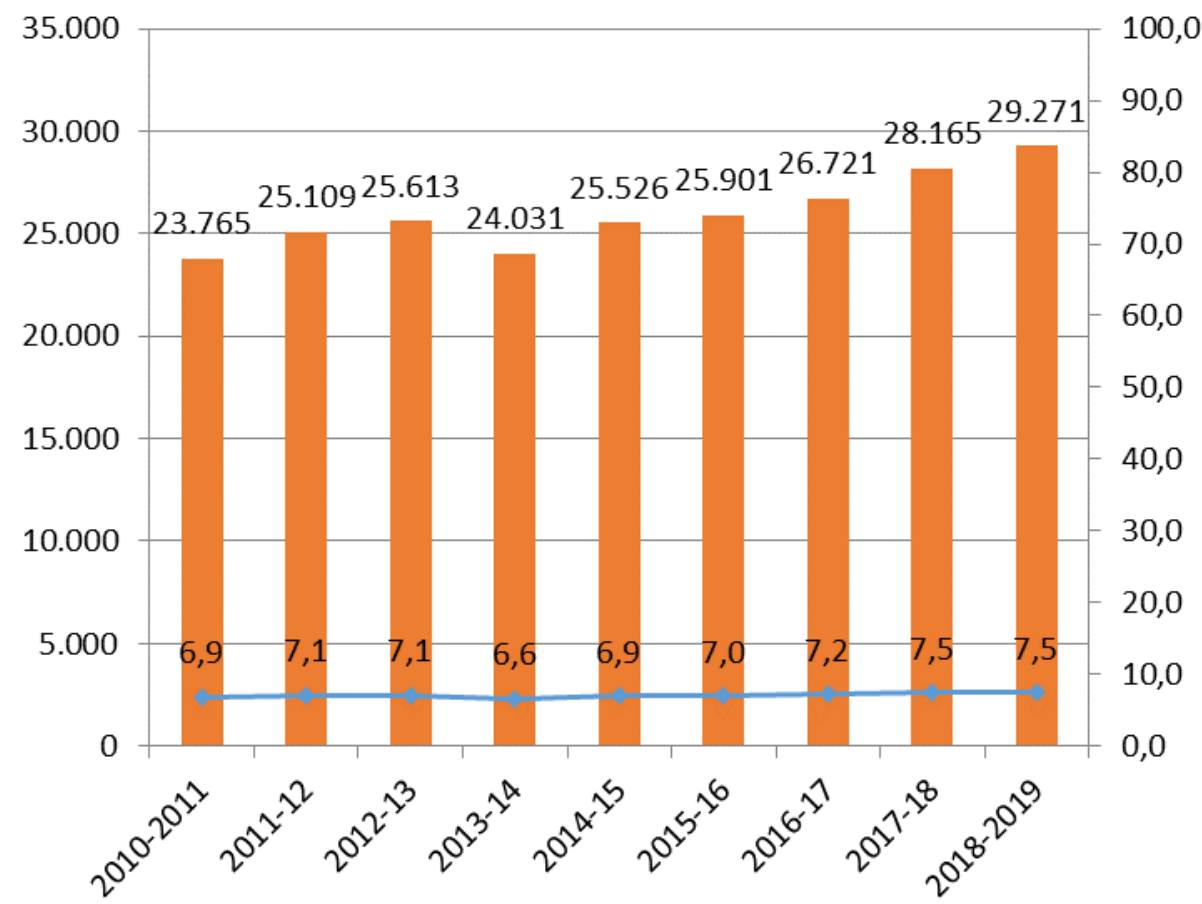

Origen extranjero $\longrightarrow$ Tasa alumnado origen extranjero

Fuente: Elaboración propia a partir de Eustat

Por tanto, estamos ante un escenario en el que el peso del alumnado de origen extranjero es relativamente bajo, sin embargo, tal y como se verá a continuación, su distribución en el sistema educativo vasco es bastante desequilibrada, provocando asimismo concentraciones en algunos estratos.

A continuación, analizaremos la distribución del alumnado de origen extranjero y autóctono en los seis estratos que se conforman en función de la titularidad de los centros, públicos y concertados, y, por otro lado, por los conformados en función de los modelos linguísticos: A público, B público, D público, A concertado, B concertado y D concertado.

Tal y como podemos apreciar en los Gráficos 3 y 4, es destacable cierta sobrerrepresentación del alumnado de origen extranjero en los centros educativos públicos, mientras que el peso del alumnado de origen extranjero es mucho menor en todos los estratos concertados. Asimismo, se suman los desequilibrios 
en cuanto a la distribución de este alumnado en los modelos lingüísticos. En el estrato A público, el 53,1\% del alumnado matriculado es de origen extranjero en cuarto de primaria, porcentaje que sube hasta un $65,2 \%$ en segundo de educación secundaria. En el polo opuesto se situaría el modelo D concertado, donde sólo un 3\% de su alumnado es de origen extranjero (3,1\% en cuarto de educación primaria y $3,4 \%$ en segundo de educación secundaria).

\section{Gráfico 3. Distribución del alumnado de origen extranjero y autóctono en los estratos que conforman el sistema educativo vasco $\left(4^{\circ}\right.$ primaria) (2017/2018)}

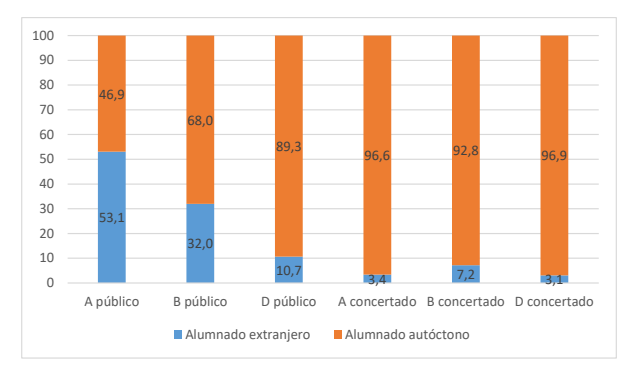

\section{Gráfico 4. Distribución del alumnado de origen extranjero y autóctono en los estratos que conforman el sistema educativo vasco ( $\left.2^{\circ} \mathrm{ESO}\right)(2017 / 2018)$}

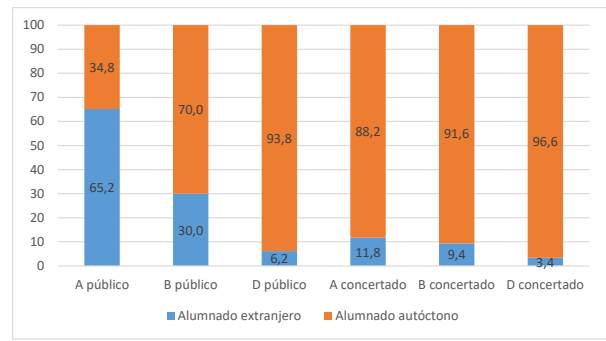

Esta situación se debe a una dualización del sistema educativo vasco preexistente que hace que el alumnado en desventaja socioeconómica sea derivado a los centros públicos en lugar de centros concertados y privados, con especial incidencia en el modelo A público. En los Gráficos 5 y $6^{3}$ se presentan los datos del Índice Socioeconómico y Cultural (ISEC) de las familias por estratos que nos permite obtener una imagen más completa de la situación del alumnado de origen extranjero en el sistema educativo vasco.

${ }^{3}$ En los Gráficos 5 y 6 sólo hemos mostrado los datos del alumnado de $4^{\circ}$ primaria por una cuestión de espacio. Los datos referentes al alumnado de $2^{\circ}$ de la ESO muestran una distribución similar al del alumnado de $4^{\circ}$ primaria en cuanto a los niveles de ISEC. 
Gráfico 5. Distribución de los niveles de ISEC por estratos (4 ${ }^{\circ}$ primaria) (2017)

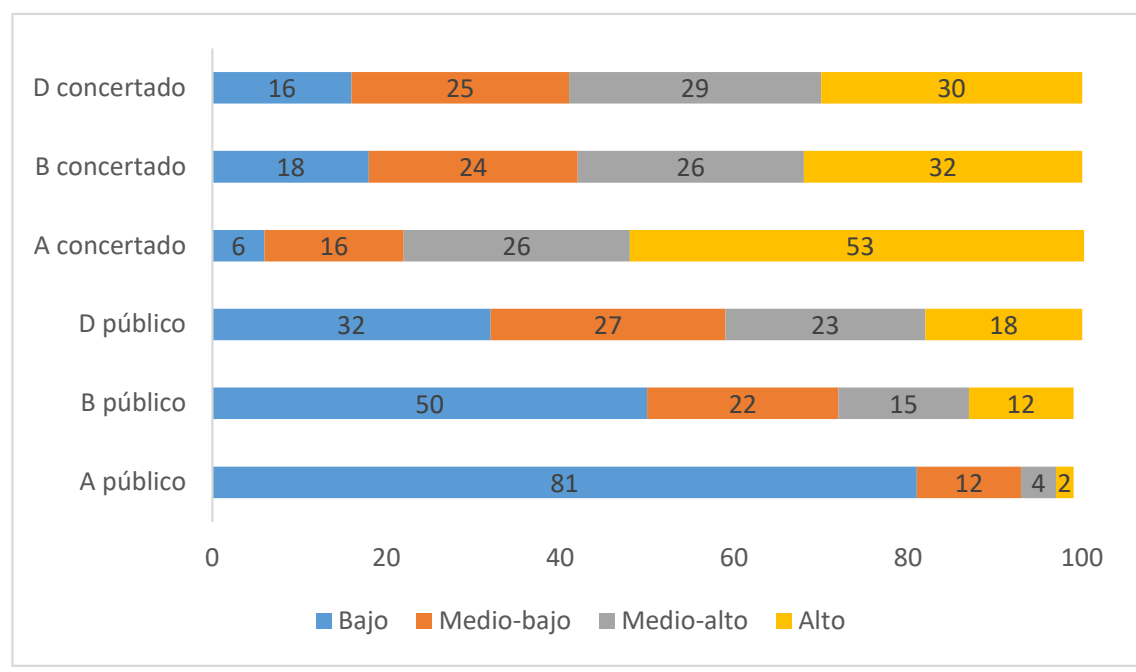

Fuente: Elaboración propia a partir de ISEI-IVEI (2017)

En el Gráfico 5 podemos observar que el alumnado procedente de las familias con ISEC más bajo se concentra, sobre todo, en el estrato A público (81\%) $\mathrm{y}$, en menor medida, en el B público (50\%) que, como acabamos de ver, son estratos que mayor porcentaje de alumnado de origen extranjero acogen. Si atendemos a la distribución de ISEC en función del origen del alumnado, de nuevo encontramos diferencias reseñables. Así, el 73,9\% del alumnado de origen extranjero matriculado en cuarto de primaria muestra un nivel bajo de ISEC, mientras que el alumnado autóctono se encuentra distribuido de manera homogénea en los cuatro niveles de ISEC. Tal y como podemos ver en el Gráfico 6, la mitad del alumnado autóctono muestra un ISEC medio alto $(26,7 \%)$ o alto $(27,1 \%)$ mientras que el porcentaje de alumnado de origen extranjero con un ISEC medio alto es de un $6,7 \%$, y de un 3,3\% en el nivel alto de ISEC (ver Gráfico 6). 


\section{Gráfico 6. Distribución de los niveles de ISEC entre el alumnado de origen extranjero y autóctono ( $4^{\circ}$ primaria) (2017)}

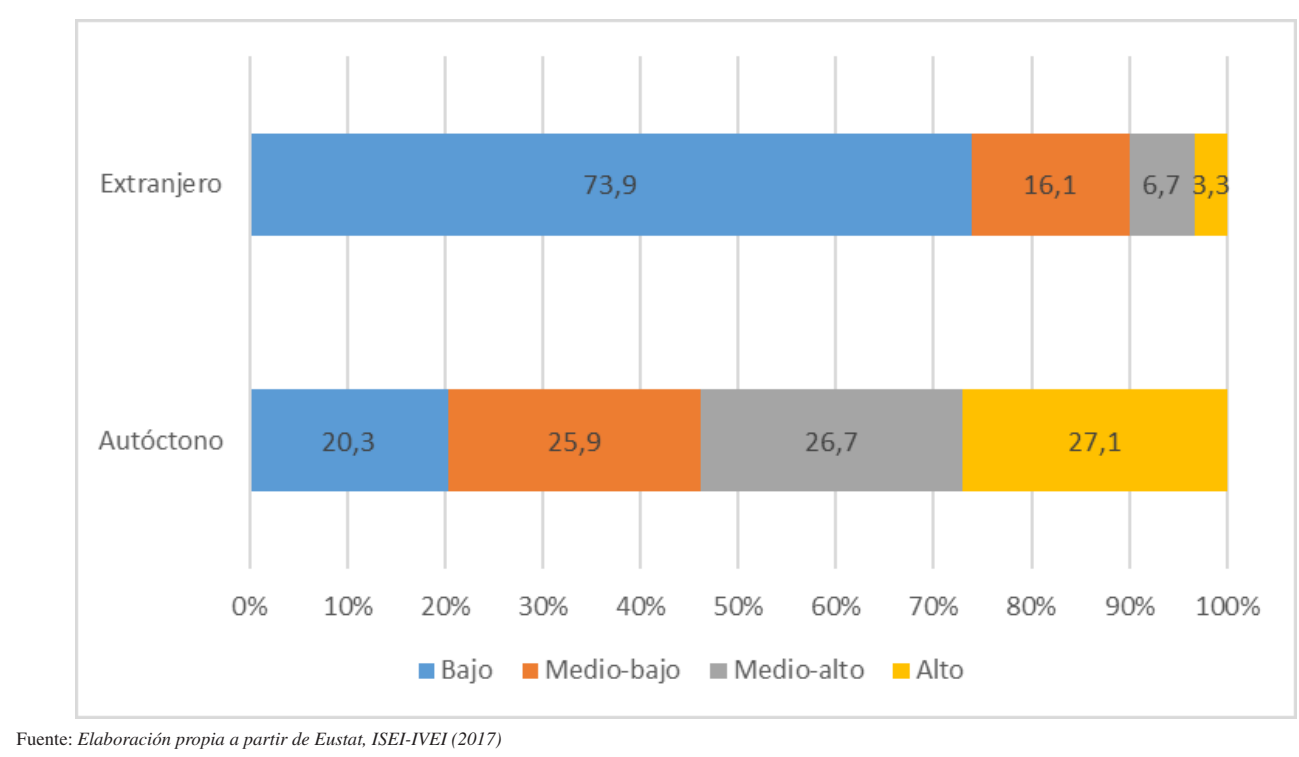

Por tanto, podemos afirmar que es en los estratos públicos donde se concentra mayoritariamente el alumnado con niveles de ISEC más bajos y, en especial, en el estrato A público donde la sobrerrepresentación del alumnado de origen extranjero es especialmente relevante. En este sentido, podemos hablar de una doble desventaja para la inclusión del alumnado de origen extranjero en un sistema tan complejo y estratificado como el vasco, donde se dan combinaciones de varios factores que pueden agravar la situación y perpetuar la situación de desventaja. 


\section{METODOLOGÍA}

Para indagar más en los factores que pueden estar asociados a una mayor concentración del alumnado inmigrante e identificar los perfiles socioeconómicos de las personas de origen extranjero en función de si consideran que sus hijos e hijas están matriculados en los centros educativos de la CAE con elevada presencia del alumnado de origen extranjero, se ha optado por explotar los datos de la Encuesta a Población Inmigrante Extranjera (EPIE) en la CAE de 2010, 2014 y 2018 realizada por el Gobierno Vasco. Dicha encuesta recoge información muy amplia acerca de diferentes dimensiones de la vida de las personas de origen extranjero residentes en la CAE, desde variables sociodemográficas hasta el proyecto migratorio y las condiciones de vida en el destino, permitiendo asimismo realizar un análisis muy completo de la realidad.

Para elaborar los perfiles hemos trabajado con los datos de la EPIE proporcionados en 2018. La muestra efectiva de personas mayores de 16 años de origen extranjero (nacionalizadas o no) residentes en la CAE asciende a 2.418, lo que supone trabajar con un error muestral máximo del $+/-1,20 \%$ para un universo estimado de 165.153 personas. Esa muestra efectiva proporciona información de 4.732 personas de origen extranjero $(\mathrm{Em}=+/-2,15 \%$, para una población estimada de 211.208 personas) proveniente de 2.418 unidades convivenciales $(\mathrm{Em}=+/-4,62 \%$, para un universo estimado de 95.651 hogares $)$ con presencia de personas de origen extranjero en la vivienda o establecimiento.

Así, con el objetivo de identificar los perfiles y variables que se asocian a la problemática de la concentración escolar, se ha utilizado el siguiente indicador subjetivo: "Indique si en el momento de incorporarse al sistema educativo vasco se dio alguna de las siguientes circunstancias: Escolarización en un centro con un número muy elevado de escolares inmigrantes". Es cierto que dicho indicador no puede ser tomado como una medida directa de la concentración del alumnado de origen extranjero, sin embargo, nos permite hacer una aproximación a una realidad desconocida hasta la fecha, que es la percepción subjetiva de las propias personas inmigrantes.

Por otra parte, la EPIE incluye otra pregunta de gran interés que hace referencia a si la familia ha sido orientada hacia un modelo linguiístico concreto, y en el caso de responder positivamente, se pide especificar el modelo (A, B o D).

En cuanto a la metodología empleada, han sido utilizadas dos técnicas de análisis de datos. Por un lado, el análisis descriptivo (tablas de contingencia) para obtener un panorama del fenómeno en la CAE y, por otro lado, ha sido empleada la técnica multivariante, análisis de segmentación AID (Asociation Interaction Detection), que permite establecer dependencia entre variables y obtener perfiles de personas en función de su puntuación en la variable dependiente (Escobar, 2007). Como técnica de análisis complementaria ha sido empleado el análisis de correspondencias simples.

Con el objetivo de seleccionar variables independientes a incluir en el modelo, se ha llevado a cabo el análisis de significación previo, que permitió selec- 
cionar aquellas que discriminan al público objeto. Así, en la Tabla 1 se pueden observar las variables incluidas en el modelo final.

Tabla 1. Variables incluidas en el modelo

\begin{tabular}{|c|c|c|}
\hline $\begin{array}{l}\text { Tipo de } \\
\text { variable }\end{array}$ & Variable & Categorías agrupadas \\
\hline Dependiente & $\begin{array}{l}\text { Escolarización en un centro con un } \\
\text { número muy elevado de escolares } \\
\text { inmigrantes en el momento de } \\
\text { incorporarse al sistema educativo } \\
\text { vasco }\end{array}$ & - Sí \\
\hline \multirow{9}{*}{ Independientes } & $\begin{array}{l}\text { En el momento actual, ¿cómo } \\
\text { definiría su familia? }\end{array}$ & $\begin{array}{l}\text { - Pobre (Muy pobre, Pobre, } \\
\text { Más bien pobre) } \\
\text { - Apañándoselas, por debajo } \\
\text { de la media/Confortable } \\
\text { (Próspera, acomodada, Rica, } \\
\text { Muy rica) }\end{array}$ \\
\hline & Situaciones de privación & $\begin{array}{l}\text { - Sí (Multidimensional, aspectos } \\
\text { básicos+ Parcial, en aspectos } \\
\text { básicos) } \\
\text { - No (Ninguna privación o no } \\
\text { grave) }\end{array}$ \\
\hline & $\begin{array}{l}\text { ¿Han percibido o solicitado } \\
\text { en los últimos } 12 \text { meses ayudas } \\
\text { económicas de instituciones } \\
\text { públicas? }\end{array}$ & - Sí \\
\hline & $\begin{array}{l}\text { Problemas de rechazo con los } \\
\text { alumnos por su raza, religión o } \\
\text { cultura }\end{array}$ & - Sí \\
\hline & $\begin{array}{l}\text { Aislamiento con el alumnado por } \\
\text { raza, religión o cultura }\end{array}$ & $\begin{array}{l}- \text { Sí } \\
\text { - No }\end{array}$ \\
\hline & $\begin{array}{l}\text { Orientación hacia un modelo } \\
\text { lingüístico concreto en el momento } \\
\text { de incorporarse al sistema } \\
\text { educativo vasco. ¿En qué modelo? }\end{array}$ & $\begin{array}{l}- \text { A } \\
\cdot \text { B } \\
\text { - D } \\
\text { - No orientado }\end{array}$ \\
\hline & $\begin{array}{l}\text { Falta de apoyo escolar para } \\
\text { alcanzar el nivel lingüístico }\end{array}$ & $\begin{array}{l}\text { - Sí } \\
\text { - No }\end{array}$ \\
\hline & $\begin{array}{l}\text { Falta de apoyo escolar para } \\
\text { alcanzar el nivel formativo }\end{array}$ & $\begin{array}{l}\text { - Sí } \\
\text { - No }\end{array}$ \\
\hline & Situación administrativa & $\begin{array}{l}\text { - Regular } \\
\text { - Irregular }\end{array}$ \\
\hline
\end{tabular}




\section{RESULTADOS}

\subsection{La escolarización del alumnado de origen extranjero en centros con elevada presencia de escolares inmigrantes}

Partiendo de la hipótesis de que el colectivo inmigrante es heterogéneo no solo culturalmente, sino también en términos socioeconómicos y de capital cultural, parece interesante indagar en las diferencias por origen, puesto que hay grupos que presentan mayores dificultades que otros.

Como se puede observar en la Tabla 2, el 16,9\% de la población de origen extranjero afirma que sus hijos e hijas están escolarizados en un centro con un número muy elevado de escolares inmigrantes. Además, la percepción de dicho problema varía de forma considerable por origen. Así, son las personas de Pakistán $(34,7 \%)$ quienes en mayor medida perciben que sus hijos e hijas están escolarizadas en un centro educativo con una presencia elevada de alumnado de origen extranjero; le siguen África Subsahariana, con el 32,8\%, Magreb $(19,4 \%)$ y Colombia, Ecuador, Perú, Bolivia, Paraguay, Brasil y otros países latinoamericanos ${ }^{4}(17,5 \%)$. Entre los orígenes con menor tasa de percepción de dicha problemática se encuentran UE Occidental $(2,2 \%)$ y Rumanía y otros UE Oriental $(9,6 \%)$.

En clave evolutiva, si comparamos estos datos con los obtenidos en las rondas anteriores de la EPIE (2010 y 2014), también podemos observar cambios importantes, donde Argentina, Chile, Uruguay y resto de orígenes latinoamericanos han tenido un importante aumento de percepción de dicho problema, que llega a duplicarse en algunos casos. En el caso de Magreb, Rumanía y otros orígenes de UE Oriental, China y África Subsahariana, por el contrario, se observa un descenso en el porcentaje de personas que perciben que sus descendientes están escolarizados en centros con un número muy elevado de escolares inmigrantes (Tabla 2).

${ }^{4}$ Bolivia, Paraguay, Brasil, República Dominicana, Venezuela, Nicaragua, Honduras, Guatemala, México, Cuba, El Salvador y Costa Rica. 
Tabla 2. Escolarización en un centro con un número muy elevado de escolares inmigrantes por área de origen, 2010/2014/2018, \% horizontales

\begin{tabular}{|l|l|l|l|}
\hline \multirow{2}{*}{ Zona de origen } & \multicolumn{3}{|l|}{$\begin{array}{l}\text { Escolarización en un centro con un número muy ele- } \\
\text { vado de escolares inmigrantes }\end{array}$} \\
\cline { 2 - 4 } & $\mathbf{2 0 1 0}$ & $\mathbf{2 0 1 4}$ & $\mathbf{2 0 1 8}$ \\
\hline UE Occidental & $6,1 \%$ & $4,5 \%$ & $2,2 \%$ \\
\hline $\begin{array}{l}\text { Rumanía y otros UE } \\
\text { Oriental }\end{array}$ & $6,9 \%$ & $20,8 \%$ & $9,6 \%$ \\
\hline Magreb & $28,8 \%$ & $31,7 \%$ & $19,4 \%$ \\
\hline Argentina, Chile, Uruguay & $19,5 \%$ & $2,3 \%$ & $14,9 \%$ \\
\hline Colombia, Ecuador, Perú & $24,7 \%$ & $18,3 \%$ & $17,5 \%$ \\
\hline $\begin{array}{l}\text { Bolivia, Paraguay, Brasil, } \\
\text { Resto América Latina }\end{array}$ & $10,5 \%$ & $6,3 \%$ & $16,8 \%$ \\
\hline China & $6,0 \%$ & $27,2 \%$ & $11,2 \%$ \\
\hline África Subsahariana & $12,8 \%$ & $45,8 \%$ & $32,8 \%$ \\
\hline Pakistán & & $37,6 \%$ & $34,7 \%$ \\
\hline Total & $14,9 \%$ & $18,6 \%$ & $16,9 \%$ \\
\hline
\end{tabular}

Fuente: Elaboración propia a partir de los datos de la EPIE 2010/2014/2018

Otra pregunta que se les hace a las personas inmigrantes es si en el momento de incorporarse al sistema educativo vasco se les orientó hacia un modelo lingüístico concreto, y en el caso de responder positivamente, se les pide especificar el modelo (A, B o D).

Respecto a la primera pregunta, tal y como se observa en la Tabla 3, el porcentaje de familias que han sido orientadas hacia un modelo lingüístico concreto a la hora de matricular a sus descendientes es bastante elevado, el 38,8\% en 2018 , a pesar de que se haya reducido casi a la mitad respecto a $2014(65,8 \%)$. Por origen, las zonas que mayor tasa presentan son China (58,8\%), Rumanía y otros UE Oriental (57,1\%), África Subsahariana (47,7\%), Bolivia, Paraguay, Brasil, Resto América Latina (46,9\%) y Pakistán (46\%). Por el contrario, el porcentaje de familias orientadas hacia un modelo lingüístico concreto en el momento de matriculación es más baja en el caso de los países de UE Occidental $(23,3 \%)$.

Por modelos, se observa que entre las familias que han sido orientadas hacia un modelo lingüístico concreto predomina el modelo $\mathrm{A}$, donde la docencia se imparte en castellano (67,9\% del total). Tal y como hemos comentado en la descripción del sistema educativo vasco, se trata de un modelo cada vez menos presente, sobre todo en las primeras etapas de escolarización. Además, como se 
ha expuesto anteriormente, el modelo A se caracteriza por una elevada presencia de alumnado procedente de los estratos sociales más vulnerables de la sociedad y con menores niveles socioeconómicos y culturales, y una alta presencia de alumnado de origen extranjero.

Tabla 3. Orientación del alumnado de origen extranjero hacia un modelo linguíístico concreto y modelo por área de origen, 2018, \% horizontales

\begin{tabular}{|c|c|c|c|c|}
\hline Zona de origen & $\begin{array}{l}\text { Orientación } \\
\text { hacia un mo- } \\
\text { delo lingüísti- } \\
\text { co concreto }\end{array}$ & A & B & $\mathrm{D}$ \\
\hline UE Occidental & $23,3 \%$ & $84,5 \%$ & $15,5 \%$ & \\
\hline Rumanía y otros UE Oriental & $57,1 \%$ & $70,0 \%$ & $17,0 \%$ & $13,0 \%$ \\
\hline Magreb & $41,7 \%$ & $68,8 \%$ & $27,5 \%$ & $3,7 \%$ \\
\hline Argentina, Chile, Uruguay & $27,9 \%$ & $68,1 \%$ & $26,2 \%$ & $5,7 \%$ \\
\hline Colombia, Ecuador, Perú & $26,8 \%$ & $53,8 \%$ & $13,7 \%$ & $32,5 \%$ \\
\hline $\begin{array}{l}\text { Bolivia, Paraguay, Brasil, } \\
\text { Resto América Latina }\end{array}$ & $46,9 \%$ & $64,2 \%$ & $20,5 \%$ & $15,3 \%$ \\
\hline China & $58,8 \%$ & $66,9 \%$ & $17,8 \%$ & $15,3 \%$ \\
\hline África Subsahariana & $47,7 \%$ & $79,5 \%$ & $13,1 \%$ & $7,4 \%$ \\
\hline Pakistán & $46,0 \%$ & $100,0 \%$ & & \\
\hline Total & $38,8 \%$ & $67,6 \%$ & $18,9 \%$ & $13,6 \%$ \\
\hline
\end{tabular}

Fuente: Elaboración propia a partir de los datos de la EPIE 2018

Por último, en cuanto a otras circunstancias mencionadas por la población inmigrante que nos ayuda a dibujar el contexto de incorporación, en la Tabla 4 se observa que, aun siendo baja, es más frecuente la falta de apoyo escolar para alcanzar el nivel linguiístico (18,3\%), siendo el porcentaje más alto entre la población de África Subsahariana (28,7\%), Magreb (26,4\%). China (22,6\%). En cuanto a la problemática de la relación exclusivamente con alumnado extranjero, se menciona por el total de $7,8 \%$ de personas de origen extranjero, y es más elevado entre la población de origen magrebí $(20,4 \%)$ y africano subsahariano $(17,4 \%)$. El rechazo por raza, religión o cultura se menciona en el 7,7\% de los casos, y se observa más entre los y las procedentes de Pakistán $(25,5 \%)$ y África Subsahariana $(18,6 \%)$, mientas que el aislamiento por este mismo motivo es mencionado por el 7,2\% del total de personas encuestadas, y está más presente en el caso de África Subsahariana (16\%). Por último, la problemática menos común es la falta de apoyo escolar para alcanzar el nivel formativo $(5,6 \%)$. En este caso destacan Pakistán (10,2\%) y Magreb (13,5\%). 
Tabla 4. Circunstancias que se dieron al incorporarse al sistema educativo vasco por origen, \% horizontales de menciones afirmativas, 2018

\begin{tabular}{|l|l|l|l|l|l|}
\hline $\begin{array}{l}\text { Zona de ori- } \\
\text { gen }\end{array}$ & $\begin{array}{l}\text { Rechazo } \\
\text { por raza, } \\
\text { religión o } \\
\text { cultura }\end{array}$ & $\begin{array}{l}\text { Aislamiento } \\
\text { por raza, } \\
\text { religión o } \\
\text { cultura }\end{array}$ & $\begin{array}{l}\text { Falta de } \\
\text { apoyo es- } \\
\text { colar para } \\
\text { alcanzar el } \\
\text { nivel lin- } \\
\text { güístico }\end{array}$ & $\begin{array}{l}\text { Falta de } \\
\text { apoyo es- } \\
\text { colar para } \\
\text { alcanzar el } \\
\text { nivel for- } \\
\text { mativo }\end{array}$ & $\begin{array}{l}\text { Relación ex- } \\
\text { clusivamente } \\
\text { con alumnado } \\
\text { extranjero }\end{array}$ \\
\hline $\begin{array}{l}\text { UE Occiden- } \\
\text { tal }\end{array}$ & $6,6 \%$ & $7,1 \%$ & $10,1 \%$ & $5,5 \%$ & \\
\hline $\begin{array}{l}\text { Rumanía } \\
\text { y otros UE } \\
\text { Oriental }\end{array}$ & $7,0 \%$ & $19,4 \%$ & $5,5 \%$ \\
\hline Magreb & $3,0 \%$ & $3,0 \%$ & $26,4 \%$ & $13,5 \%$ & $20,4 \%$ \\
\hline $\begin{array}{l}\text { Argentina, } \\
\text { Chile, Uru- } \\
\text { guay }\end{array}$ & $\begin{array}{l}\text { Colombia, } \\
\text { Ecuador, } \\
\text { Perú }\end{array}$ & $9,2 \%$ & $7,8 \%$ & $11,9 \%$ & $3,8 \%$ \\
\hline $\begin{array}{l}\text { Bolivia, Para- } \\
\text { guay, Brasil, } \\
\text { Resto }\end{array}$ & $9,2 \%$ & $8,4 \%$ & $19,7 \%$ & $5,7 \%$ & $6,0 \%$ \\
\hline China & $15,8 \%$ & $9,0 \%$ & $22,6 \%$ & $2,5 \%$ & $3,8 \%$ \\
\hline $\begin{array}{l}\text { África Subsa- } \\
\text { hariana }\end{array}$ & $18,6 \%$ & $16,0 \%$ & $28,7 \%$ & $6,9 \%$ & $17,4 \%$ \\
\hline Pakistán & $25,5 \%$ & $8,7 \%$ & $18,9 \%$ & $10,2 \%$ & $7,8 \%$ \\
\hline Total & $7,7 \%$ & $7,2 \%$ & $18,3 \%$ & $5,6 \%$ & \\
\hline
\end{tabular}

Fuente: Elaboración propia a partir de los datos de la EPIE 2018

\subsection{Perfiles de las familias del alumnado de origen extranjero matriculado en centros educativos con muy elevada presencia de escolares inmigrantes}

Tras el análisis de las características del alumnado de origen extranjero matriculado en los centros educativos de la CAE, se ha procedido a analizar los datos en su conjunto confeccionando un modelo que incluya las variables más relevantes que permiten acercarse al fenómeno en cuestión. Como resultado de dicho análisis, mediante la técnica multivariante de Detector Automático de Interacciones (CHAID) que permite detectar perfiles de personas inmigrantes encuestadas en función de la variable dependiente, la consideración de escola- 
rización en un centro con un número muy elevado de escolares inmigrantes, en este caso, se ha obtenido un árbol de decisiones o de segmentación.

De las variables presentadas inicialmente (ver Tabla 1), en el modelo final fueron incluidas las siguientes por tener mayor capacidad discriminante:

- I nivel: Haber percibido ayudas económicas en los últimos 12 meses $(p<.001)$;

- II nivel: Orientación hacia modelo lingüístico $(p<.001)$;

- III nivel: Falta de apoyo escolar para alcanzar nivel lingüístico $(p<.001)$; Situaciones de privación $(p<.001)$; Percepción de situación económica de hogar $(p<.001)$.

El porcentaje de casos clasificados correctamente de este modelo asciende al $84,1 \%$, lo que puede ser considerado un indicador relativamente alto.

Con estas variables obtenemos 17 perfiles, descripciones de tipos ideales, que se observan en los nodos finales de la Imagen 1, ordenados de mayor a menor porcentaje de las personas que han respondido que su hijo o hija se escolarizaron en un centro con un número muy elevado de escolares inmigrantes en el momento de incorporarse al sistema educativo vasco. 

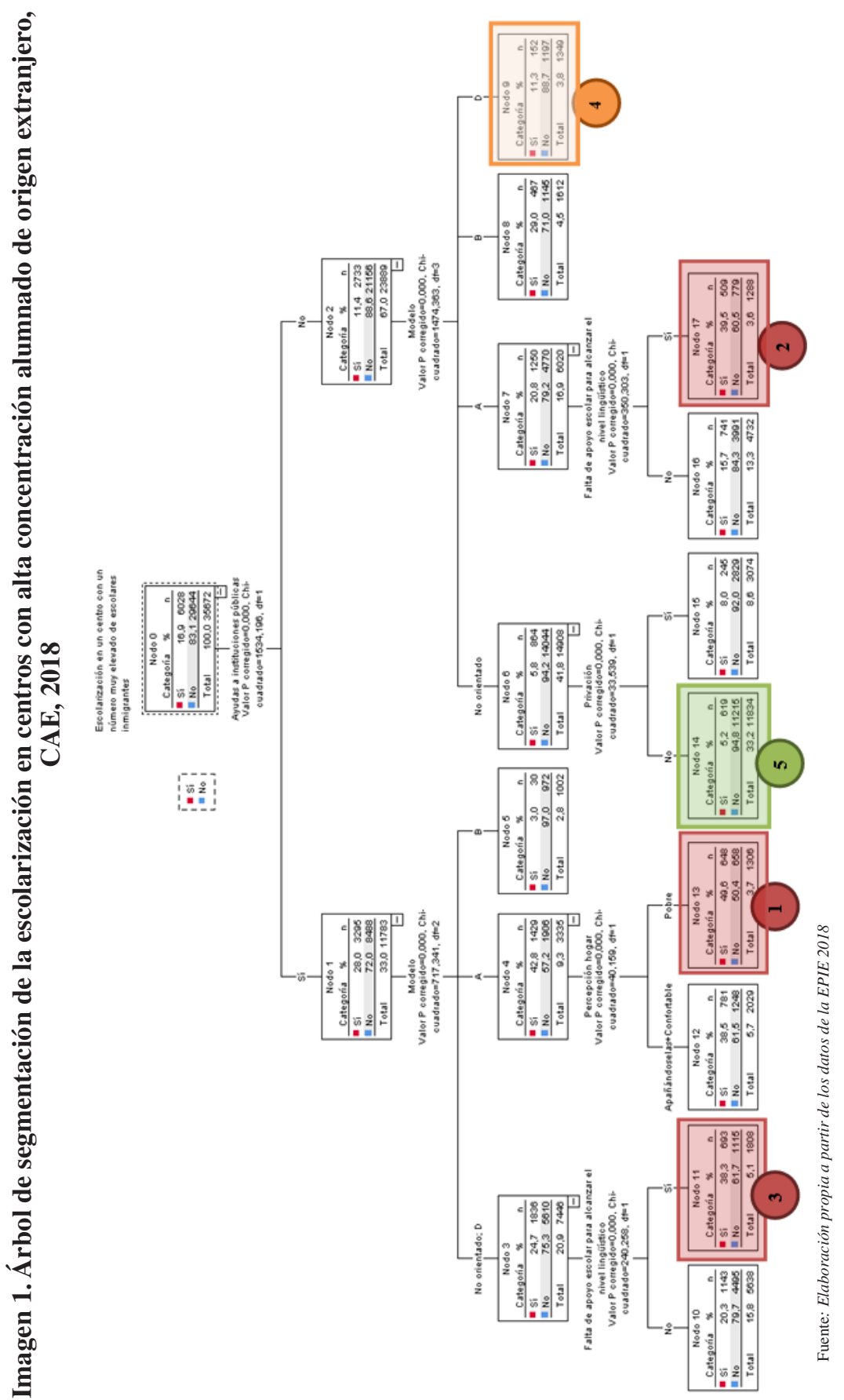

EMPIRIA. Revista de Metodología de Ciencias Sociales. N. 51 mayo-agosto, 2021, pp. 15-43.

ISSN: 1139-5737, DOI/ empiria.51.2021.30806 
A continuación, solo se describen los cinco perfiles más significativos que ayudan a comprender qué características tienen las personas que más señalan que sus hijos/as están en centros con elevada tasa de alumnado de origen extranjero. Entre los perfiles con mayor porcentaje de menciones de escolarización de sus descendientes en centros con elevada presencia de alumnado de origen extranjero se encuentra el Perfil 1, con el 49,6\% de respuestas afirmativas. Este perfil está compuesto por personas que han percibido o solicitado en los últimos 12 meses ayudas económicas, han sido orientadas hacia el modelo lingüístico A y describen su situación económica de hogar como pobre (Tabla 5).

El Perfil 2 también presenta una alta presencia del problema mencionado, el 39,5\% de respuestas afirmativas. Lo conforman aquellas personas que no han percibido o solicitado en los últimos 12 meses ayudas económicas, han sido orientadas hacia el modelo lingüístico A y afirman haber tenido problemas de falta de apoyo escolar para alcanzar el nivel lingüístico.

Otro perfil con altos porcentajes de personas que señalan que sus hijos/as están en centros con elevada tasa de alumnado de origen extranjero es el Perfil 3. Al igual que en el caso del Perfil 1, las personas de este perfil han percibido o solicitado en los últimos 12 meses ayudas económicas, sin embargo, no han sido orientadas hacia ningún modelo lingüístico o han sido orientadas hacia el modelo D y, además, afirman haber tenido problemas de falta de apoyo escolar para alcanzar el nivel lingüístico.

El Perfil 4 presenta unos porcentajes intermedios (11,3\%), y está compuesto por personas que no han solicitado o percibido en los últimos 12 meses ayudas económicas y han sido orientadas hacia el modelo lingüístico D en el momento de incorporarse al sistema educativo vasco.

Por último, encontramos el Perfil 5 que se caracteriza por una tasa muy baja de personas que afirman que sus hijos/as han sido escolarizados en un centro con un número muy elevado de escolares inmigrantes, el 5,2\%. Son aquellas personas que no han solicitado o percibido en los últimos 12 meses ayudas económicas, no han sido orientados hacia ningún modelo concreto en el momento de incorporarse al sistema educativo vasco y no han tenido situaciones de privación grave o leve. 
Tabla 5. Resumen de perfiles por porcentaje de escolarización en centros con alta concentración alumnado de origen extranjero, CAE, 2018

\begin{tabular}{|l|l|l|l|}
\hline Perfil & Características & \multicolumn{2}{|c|}{$\begin{array}{l}\text { \% escolarización cen- } \\
\text { tros alta concentración }\end{array}$} \\
\hline $\mathbf{1}$ & Ayudas sí, Orientado A, Pobre & $49,7 \%$ & \multirow{2}{*}{ Alta } \\
& $\begin{array}{l}\text { Ayudas no, Orientado A, Falta apoyo lingüís- } \\
\text { tico }\end{array}$ & $39,5 \%$ & \\
\hline $\mathbf{3}$ & $\begin{array}{l}\text { Ayudas sí, No orientado o D, Falta apoyo lin- } \\
\text { güístico }\end{array}$ & $38,3 \%$ & Media \\
\hline $\mathbf{4}$ & Ayudas no, Orientado D & $11,3 \%$ & Baja \\
\hline $\mathbf{5}$ & Ayudas no, No orientado, No privación & $5,2 \%$ & . \\
\hline
\end{tabular}

Fuente: Elaboración propia a partir de los datos de la EPIE 2018

Por tanto, se puede observar que dentro de las variables que mejor discriminan a la población en función de si sus descendientes han sido escolarizados en un centro con un número muy elevado de escolares inmigrantes, hay diferencias significativas entre diferentes perfiles, donde una peor situación económica y el hecho de haber sido orientados hacia el modelo A se asocia a una mayor probabilidad de compartir centros educativos con un número muy elevado de alumnado de origen extranjero. Además, la incidencia de dicho problema parece estar relacionada con la falta de apoyo escolar para alcanzar el nivel lingüístico, ya sea en castellano o euskera.

A continuación, se ha analizado qué zonas de procedencia están más asociadas con la pertenencia a cada perfil. Para ello, nos hemos apoyado en las tablas de contingencia y en un análisis factorial de correspondencias simples (AFC) (Gráfico 7). 


\section{Gráfico 7. Análisis de Correspondencias Simples}

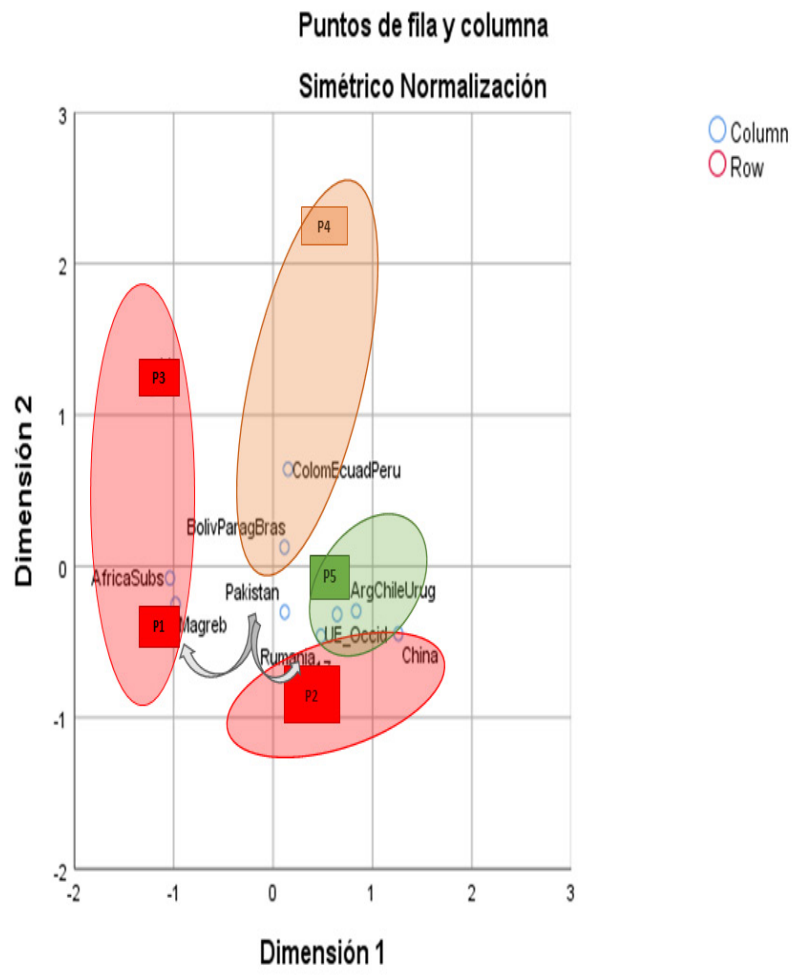

Nota: $\rrbracket^{2}(80)=29867,119 p<.001$

Fuente: Elaboración propia

En este análisis factorial de correspondencias simples hemos extraído dos dimensiones que explican el 90,4\% de la varianza. La primera dimensión, que probablemente se asocia con la Vulnerabilidad económica, explica casi toda la varianza (el 81,3\%), mientras que la segunda dimensión relacionada con la Falta de apoyo lingüístico, tiene poco valor explicativo (el 8,7\% restante).

Así, la asociación entre zonas de procedencia y perfiles sociodemográficos

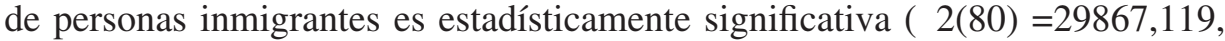
sig. 0,000).

Aunque inicialmente en el análisis de segmentación fueron establecidos cinco perfiles que mayor número de casos aglutinan, la solución del AFC sugiere cuatro grandes grupos.

Así, al Perfil 1 y Perfil 3 se asocian las familias procedentes de Magreb y África Subsahariana, que estarían en el cuadrante izquierdo, -el opuesto al cua- 
drante correspondiente al Perfil 5-. En el caso de Pakistán, compartiría algunas características de la Dimensión 2 con Magreb y África Subsahariana del Perfil 1.

El Perfil 2 está asociado fundamentalmente a personas de origen chino, rumano y otras procedencias de Europa oriental, que parece compartir con el Perfil 1 las características de la Dimensión 2 (Vulnerabilidad económica), aunque al mismo tiempo comparte con personas de Argentina, Chile, Uruguay y UE Occidental algunas características de la Dimensión 1 (Falta de apoyo lingüístico).

Por último, el Perfil 5 se asocia más a las personas de Argentina, Chile, Uruguay y UE Occidental, que presentan porcentajes muy bajos de personas que afirman que sus descendientes fueron escolarizados en centros con alta concentración alumnado de origen extranjero. Este perfil se ubica en el extremo opuesto a los Perfiles 1 y 3 en la Dimensión 1. En este sentido, el Perfil 4 se asocia más con Bolivia, Paraguay y Brasil, Colombia, Ecuador y resto de países latinoamericanos, y estaría en el cuadrante opuesto al del Perfil 2 y 1 en la Dimensión 2, pero compartiría características de la Dimensión 1 con el Perfil 2 y 5.

\section{CONCLUSIONES}

La inmigración constituye uno de los actuales fenómenos sociales, culturales y económicos de mayor trascendencia para las sociedades occidentales. El sistema educativo vasco tampoco es ajeno a estas transformaciones. De hecho, esta investigación ha puesto de relieve que, aunque el porcentaje del alumnado de origen extranjero en el sistema educativo no supera el $8 \%$ sobre el total, existen ciertos desequilibrios en cuanto a su distribución por tipo de centro y modelos lingüísticos. Así, el alumnado de origen extranjero se concentra en mayor medida en los centros públicos y en el modelo lingüístico $\mathrm{A}$, donde la docencia se imparte en castellano, y donde se concentra el alumnado con índices socioeconómicos y culturales más bajos.

En este sentido, el alumnado de origen extranjero matriculado en este segmento del sistema educativo se encuentra en una situación de doble desventaja. Por un lado, está la desventaja derivada de la situación socioeconómica en la que se encuentra, a lo que se suma la desventaja de su condición de inmigrante, relacionada en muchas ocasiones con las dificultades con los idiomas oficiales, la situación administrativa irregular, la inestabilidad laboral de sus progenitores y la segregación residencial.

Es por ello que se ha decidido ahondar más en la realidad del alumnado de origen extranjero en la CAE, analizando los principales perfiles socioeconómicos de aquellas familias que en la Encuesta a la Población Inmigrante Extranjera en la CAE (EPIE 2010/2014/2018) afirman que sus hijos e hijas están matriculados en centros con elevada presencia del alumnado de origen extranjero.

Como resultado, el análisis ha revelado cinco perfiles más importantes que se diferencian en función de si la unidad convivencial ha recibido ayudas sociales en los últimos 12 meses, así como si ha sido orientada hacia algún modelo lingüístico en concreto a la hora de matricularse, la situación económica del hogar 
y, por último, la falta de apoyo escolar para alcanzar nivel lingüístico. Así, el perfil con mayor incidencia de la problemática de la matriculación en centros con elevada presencia de escolares inmigrantes se caracteriza por tener las condiciones más desventajosas como son el hecho de percibir ayudas sociales, que indica una situación económica precaria, así como las situaciones de privación graves. Además, se trata de familias que han sido orientadas hacia el modelo A, que se caracteriza por una mayor tasa de personas con ISEC bajo. Este perfil se asocia más a personas procedentes de África Subsahariana y Magreb y, en menor medida, Pakistán.

Otro de los perfiles que afirma en mayor medida que sus hijos e hijas están matriculados en centros con alta concentración de alumnado de origen extranjero es parecido al perfil anteriormente mencionado, siendo también familias que han sido orientadas hacia el modelo $\mathrm{A}$, pero que no han percibido ninguna ayuda social en los últimos 12 meses, y, además, perciben falta de apoyo escolar para alcanzar el nivel lingüístico. Este perfil también está presente entre la población china y, en parte, la rumana.

Por otra parte, tenemos el perfil con una incidencia alta de familias que afirman que sus descendientes están en centros con alta concentración de alumnado de origen extranjero compuesto por personas que han percibido ayudas sociales en los últimos 12 meses, no han sido orientadas hacia ningún modelo lingüístico $\mathrm{y}$, además, perciben falta de apoyo escolar para alcanzar el nivel lingüístico. Al igual que el primer perfil, está compuesto básicamente por personas procedentes de África Subsahariana y Magreb.

El perfil caracterizado por una incidencia media del problema es más frecuente entre las personas que no han percibido ayudas sociales en los últimos 12 meses y han sido orientadas hacia el modelo D. Este perfil está conformado sobre todo por personas de Bolivia, Paraguay y Brasil, Colombia, Ecuador y resto de países latinoamericanos.

En el otro extremo, y a diferencia del resto de los perfiles, se han identificado aquellas familias cuya situación económica es más favorable, no han sido orientadas hacia ningún modelo lingüístico y no muestran ninguna situación de privación. Entre ellas, están Argentina, Chile, Uruguay y UE Occidental, procedencias donde esta problemática es prácticamente inexistente.

En resumen, el análisis ha demostrado la capacidad discriminatoria de variables socioeconómicas como la situación económica del hogar y situaciones de privación, que se asocian a una mayor o menor presencia de la escolarización en centros con alta concentración de alumnado de origen extranjero. Sin embargo, el análisis ha relevado que el alumnado de origen extranjero no conforma un bloque homogéneo puesto que se han podido observar diferencias relevantes según el origen.

Además, los resultados confirman que la hipotética libertad de elección de centro se ve limitada en los perfiles que hemos analizado. Como hemos señalado anteriormente, las barreras informativas y económicas afectan a las familias de menor nivel socioeconómico en el proceso de selección del centro escolar. En este sentido, el modelo lingüístico que conforma uno de los ejes más importantes 
en cuanto a la desigualdad se refiere, se ha demostrado como una variable con alto poder discriminatorio a la hora de analizar la distribución desigual en el sistema escolar vasco. Así, se ha podido ver que, en muchos casos, las familias con alta incidencia de esta problemática declaran haber sido orientadas hacia el modelo A y tienen problemas para alcanzar el nivel lingüístico. Esta segunda estratificación derivada de los modelos lingüísticos hace que las características del fenómeno de la concentración escolar trasciendan de las dinámicas más generalizadas de distribución del alumnado en función de la titularidad de los centros. Al mismo tiempo, y como señala Barquín (2011), difícilmente se puede hablar de integración si estos niños y niñas van a pasar su vida escolar en centros en los que apenas tienen contacto con los hijos e hijas de personas autóctonas y si, además, van a salir de la escuela obligatoria con menos capacidades que estos. Está claro que una escolarización en la que no se aprende euskara tiene como consecuencia una menor posibilidad de integración social y laboral en la sociedad vasca en el futuro.

De esta manera, podemos afirmar que la concentración educativa en determinados segmentos del sistema educativo se produce no solo por dinámicas propias de clases sociales y/o residenciales, sino que la orientación que las familias de origen extranjero reciben desde las instituciones contribuye a que esta situación se agrave con todas las implicaciones que ello supone.

Aunque nuestro estudio se ha basado en datos del alumnado de origen extranjero, consideramos que limitar o entender que las dinámicas de concentración y segregación repercuten solo a la población inmigrante es un error que nos impide realizar un diagnóstico certero de la realidad educativa vasca. Como hemos podido ver, se produce un solapamiento de factores que hace que podamos hablar de segregación social en las escuelas vascas que transciende la segregación étnica o por origen. Los diferentes datos de ISEC, así como los perfiles más afectados por las dinámicas de concentración escolar nos muestran que la base de la segregación no es unidimensional ni homogénea. Tal y como indica Barquín (2018), la segregación escolar por clase social estaba ya más que presente, pero con la llegada de la inmigración se ha agudizado y, sobre todo, se ha visibilizado la separación. De esta manera, cuando hablamos de concentración de alumnado de origen extranjero, estamos hablando de un alumnado con un perfil socioeconómico concreto. El alumnado de origen extranjero que se encuentra en condiciones socioeconómicas favorables se enfrenta en menor medida a esa problemática. Así, en las escuelas con elevada presencia de alumnado de origen extranjero, podemos encontrar también otros colectivos con bajo perfil socioeconómico y alumnado con necesidades educativas específicas.

Además, y más allá de las consecuencias que la segregación escolar produce en el rendimiento escolar del alumnado de origen extranjero y de aquel alumnado con un menor capital social y cultural y unas condiciones socioeconómicas desfavorables, también tenemos que señalar las consecuencias que en clave de integración y cohesión social provoca la desigual distribución del alumnado.

Entendemos que algunas de las medidas adoptadas en la CAE, como el cambio que limita la posibilidad de que determinados centros usen arbitrariamente 
las plazas de matriculación durante el curso escolar, o los nuevos criterios de admisión en centros públicos que favorecen que familias de rentas superiores puedan matricularse en esos centros, podrían favorecer una distribución más equitativa del alumnado. Por todo ello, resulta imprescindible continuar con el análisis del fenómeno de la concentración del alumnado inmigrante en las aulas vascas, que como hemos podido apreciar supera la dicotomía público/privado de la titularidad de los centros y añade un nuevo eje de diferenciación que se sustenta en los modelos lingüísticos. Además, no podemos olvidar que se trata de un colectivo heterogéneo en cuanto a su situación socioeconómica y administrativa que pone de relieve la necesidad de indagar en las particularidades que presentan, así como las consecuencias que se derivan de ello.

\section{BIBLIOGRAFÍA}

AJA, E. (2000): “La regulación de la educación de los inmigrantes”, en La inmigración extranjera en España. Los retos educativos, Barcelona, Fundación La Caixa, pp. 6998.

ALLEN, R. (2007): "Allocating pupils to their nearest secondary school: The consequences for social and ability stratification”, Urban Studies, 44(4), pp. 751-770.

BARQUÍN, A. (2018, febrero 3): "Hijas e hijos de inmigrantes en las escuelas vascas. ¿Es hoy un alumnado “deseado"?”, El Diario, disponible en: http://www.eldiario.es/ norte/vientodelnorte/Hijas-inmigrantes-escuelas-alumnado-deseado_6_718538151. html [consulta: 3-7-2019].

BARQUÍN, A. (2011): "El futuro modelo lingüístico único y la escolarización de los alumnos de origen inmigrante (1)", Revista Mugak, 39, disponible en http://www. mugak.eu/revista-mugak/no-39/el-futuro-modelo-linguistico-unico-y-la-escolarizacion-de-los-alumnos-de-origen-inmigrante-1 [consulta: 3-7-2019].

BERNAL, J. L. y VERA, C. R. (2019): "La elección de centro como mecanismo de segregación social", Revista Fuentes, 21(2), pp. 189-200.

BIFULCO, R., LADD, H. F. y ROSS, S. L. (2009): "Public school choice and integration evidence from Durham, North Carolina", Social Science Research, 38(1), pp. $71-85$.

BONAL, X. y ZANCAJO, A. (2020): "Elección de Escuela, Movilidad y Segregación Escolar del Alumnado Vulnerable en Barcelona", REICE. Revista Iberoamericana Sobre Calidad, Eficacia y Cambio En Educación, 18(4), pp. 197-218.

BONAL, X. y BELLEI, C. (eds.) (2018): Understanding school segregation: patterns, causes and consequences of spatial inequalities in education, London, Bloomsbury.

BOTERMAN, W. R. (2013): "Dealing with diversity: Middle-class family households and the issue of "black" and "white" schools in Amsterdam", Urban Studies, 50(6), pp. 1130-1147.

BURGESS, S., MCCONNELL, B., PROPPER, C. y WILSON, D. (2004): Sorting and choice in English secondary schools, Bristol, Centre for Market and Public Organisation.

CALERO, J. y CHOI, A. (2019): Efectos de la inmersión lingüística sobre el alumnado castellanoparlante en Cataluña, Barcelona, Fundación Europea Sociedad y Educación. 
CAPELLÁN DEL TORO, L., GARCÍA, J. F., OLMOS, A. y RUBIO, M. (2013): “Sobre agrupamiento, concentración, segregación o guetización escolar: claves para un análisis interpretativo de tales situaciones y procesos", Avances en Supervisión Educativa. Revista de la Asociación de Inspectores de Educación de España, 18, pp. $1-27$.

COLOM ORTIZ, F. (2012): "Desigualdades en el sistema educativo no universitario de la ciudad de Valencia", en Segregaciones y construcción de la diferencia en la escuela, Madrid, Trotta, pp. 43-60.

EL-HABIB, B., JIMÉNEZ-DELGADO, M., RUIZ CALLADO, R. y JAREÑO RUIZ, D. (2016): “Composición escolar y expectativas del alumnado por origen y etnia: una aproximación a la segregación escolar extraoficial", RASE: Revista de la Asociación de Sociología de la Educación, 9(1), pp. 59-77.

ENTORF, H. y LAUK, M. (2008): "Peer effects, social multipliers and migrants at school: An international comparison", Journal of Ethnic and Migration Studies, 34, pp. 633-654.

ESCOBAR, M. (2007): El análisis de segmentación: técnicas y aplicaciones de los árboles de clasificación, Cuadernos Metodológicos, 39, Madrid, CIS.

ETXEBERRIA, F., GARMENIA, J., MURUA, H. y ARRIETA, E. (2019): Alumnado inmigrante y competencia plurilingüe en la escuela inclusiva, disponible en: https:// edoc.hu-berlin.de/handle/18452/21343 [consulta: 26-3-2021]

ETXEBERRIA F., GARMENDIA, J., MURUA, H. y ARRIETA, E. (2018): “Acogida del alumnado inmigrante recién llegado en la escuela inclusiva. El caso de Cataluña, País Vasco y Francia", RES, Revista de Educación Social, 27, pp. 93-119.

FRANKENBERG, E. (2013): "The role of residential segregation in contemporary school segregation", Education and Urban Society, 45 (5), pp. 548-570.

GARCÍA CASTAÑO, F. J. y OLMOS ALCARAZ, A. (2012): Segregaciones y construcción de la diferencia en la escuela, Madrid, Editorial Trotta.

GARRETA, J. (2011): "Las experiencias escolares de la Inmigración”, Papers, 96 (1), pp. 205-223.

GORARD, S. y SMITH, E. (2004): “An international comparison of equity in education systems", Comparative Education, 40, 1, pp. 15-28.

JENKINS, S.P., MICKLEWRIGHT, J. y SCHNEPF, S. V. (2008): "Social segregation in secondary schools: how does England compare with other countries?", Oxford Review of Education, 34, 1, pp. 21-37.

KYE, S. H. (2018): "The persistence of white flight in middle-class suburbia. Social Science Research", 72, pp. 38-52.

LEE, Y., ZHANG, Y. y STANKOV, L. (2019): "Predictive Validity of SES Measures for Student Achievement", Educational Assessment, 24:4, pp. 305-326.

LÓPEZ-FALCÓN, D. y BAYONA, J. (2012): "Segregación escolar y residencial en Barcelona: del boom migratorio al asentamiento", en Segregaciones y construcción de la diferencia en la escuela, Madrid, Trotta, pp. 21-42.

MANCEBÓN-TORRUBIA, M. J., y PÉREZ-XIMÉNEZ, D. (2010): “Una valoración del grado de segregación socioeconómica existente en el sistema educativo español. Un análisis por comunidades autónomas a partir de PISA 2006", Regional and Sectorial Economic Studies, 10, 3, pp. 129-148.

MANCEBÓN- TORRUBIA, M. J., y PÉREZ-XIMÉNEZ, D. (2009): “Segregación escolar en el sistema educativo español. Un análisis a partir de PISA 2006”, Investigaciones de Economía de la Educación, 4, pp. 63-77. 
MURILLO, F. J. y GRAÑA, R. (2020): “¿Segregación Escolar por Nivel Socioeconómico o por Nivel de Estudios de los Padres? ", REICE. Revista Iberoamericana Sobre Calidad, Eficacia Y Cambio En Educación, 18(4), pp. 9-29.

MURILLO, F. J. y MARTÍNEZ-GARRIDO, C. (2018): "Magnitud de la segregación escolar por nivel socioeconómico en España y sus Comunidades Autónomas y comparación con los países de la Unión Europea”, RASE. Revista de Sociología de la Educación, 11(1), pp. 37-58.

MURILLO, F. J. y BELAVI, G. (2018): "Segregación escolar de los estudiantes extranjeros pobres en España”, Scripta Nova. Revista Electrónica de Geografía y Ciencias Sociales, XXII (603), pp. 1-27.

MURILLO, F.J., MARTÍNEZ-GARRIDO, C. y BELAVI, G. (2017): "Segregación escolar por origen nacional en España”, OBETS. Revista de Ciencias Sociales, 12 (2), pp. 395-423.

ORFIELD, G. y LEE, C. (2005): Why segregation matters: poverty and educational inequality, Boston, MA, Harvard University Press.

PELÁEZ, C. (2012): "La escuela, un espacio simbólico que construir: Estigmas y estrategias de los agentes en los procesos de segregación étnica y escolarización", en Segregaciones y construcción de la diferencia en la escuela, Madrid, Trotta, pp. 6182.

SALINAS, J. y SANTÍN, D. (2012): "Selección escolar y efectos de la inmigración sobre los resultados académicos españoles en PISA 2006”, Revista de Educación, 358, pp. 382-405.

SCHNEPF, S.V. (2007): “Immigrants' educational disadvantage: an examination across ten countries and three surveys", Journal of Population Economics, 20 (3), pp. 527 545.

STEPHAN, W. (2013): School desegregation: Past, present, and future, Nueva York, NY, Springer.

STROUB, K.J. y RICHARDS, M.P. (2013): "From resignation to reintegration: Trends in the racial/ethnic segregation of metropolitan public schools, 1993-2003", American Educational Research Journal, 50 (3), pp. 497-532. 
